Review Article

\title{
PHARMACOVIGILANCE IN THE ERA OF COVID-19: A CONCISE REVIEW OF THE CURRENT SCENARIO, IMPLICATIONS, AND CHALLENGES
}

\author{
SIDDHARTHA DUTTA, SNEHA AMBWANI*, GOVIND MISHRA, HINA LAL, KISHNA RAM, TARUN KUMAR
}

1Department of Pharmacology, All India Institute of Medical Sciences (AIIMS), Jodhpur 342005, Rajasthan, India

Email: sr_ambwani@yahoo.com

Received: 10 Feb 2021, Revised and Accepted: 20 Mar 2021

\begin{abstract}
The pandemic of Coronavirus Disease 2019 (COVID-19) has now affected the entire globe which was first surfaced in China in December 2019. In absence of effective therapy to manage COVID-19, repurposed therapies were being used to manage the condition. In view of an urgent need for definitive therapy, multiple repurposed drugs, and investigational drug candidates are being tried in clinical trials which may lead to the emergence of unknown short term and long term adverse drug reactions (ADRs), and hence it is crucial to assess the safety of the tried therapeutic interventions. The lag in the pharmacovigilance activities in the midst of this pandemic fosters under-reporting of ADRs. Difficulty in causality assessment due to factors like wide variations in clinical presentation, concomitant use of multiple drugs, associated comorbidities, drug-drug and drug-disease interaction which forestalls the appropriate causality assessment. Hydroxychloroquine, a repurposed antimalarial drug has been a part of hue and cry at present because of its in-question safety in patients with cardiac disorders. National and International Drug monitoring centers have stressed upon reporting of ADRs and to boost up the process and come up with various recommendations. We can overcome these issues by working cohesively, motivating HCPs and patients to report ADRs electronically, and by setting up dedicated pharmacovigilance rapid response team to tackle the issues at the earliest.
\end{abstract}

Keywords: Pharmacovigilance, ADR reporting, COVID-19, Drug repurposing, Hydroxychloroquine

(C) 2021 The Authors. Published by Innovare Academic Sciences Pvt Ltd. This is an open access article under the CC BY license (https://creativecommons.org/licenses/by/4.0/) DOI: https://dx.doi.org/10.22159/ijap.2021v13i3.41063. Journal homepage: https://innovareacademics.in/journals/index.php/ijap

Speedy peer review was done as the subject of the manuscript was related with pandemic.

\section{INTRODUCTION}

In current times of pandemic of Coronavirus Disease 2019 (COVID19), the entire globe is fighting a war against the severe acute respiratory syndrome coronavirus 2 (SARS-CoV-2) [1]. The COVID19 started in the Wuhan district of China with few cases of pneumonia having unfamiliar etiology and later it got spread to other countries of the world following which on March 11, 2020, it was declared as a global pandemic by the World Health Organization (WHO) [1-3]. As of $15^{\text {th }}$ July 2020, a total of $12,964,809$ confirmed cases of COVID-19, including 5,70,288 deaths have been confirmed by the WHO. As per WHO, the United States of America, Europe, Eastern Mediterranean, South-East Asia are worst hit by this pandemic apart from the reach-in African and Western Pacific regions [4]. COVID-19 most commonly presents with symptoms like fever, dry cough, and fatigue $[5,6]$. Having diverse clinical presentations, it can also present with less common symptoms like myalgia, rhinorrhoea, headache, conjunctivitis, sore throat, diarrhoea, anosmia or ageusia, skin rash, or discoloration of fingers or toes [6-8]. The respiratory symptoms can range from mild flu to severe respiratory distress which can end up in progressive respiratory failure and sometimes death [7, 9]. The laboratory findings show lymphopenia, elevation in lactate dehydrogenase levels, and also associated with elevation of inflammatory markers such as C-reactive protein, D-dimer, ferritin, and interleukin-6 [9, 10]. The radiology findings with computed tomography (CT) scans show bilateral pulmonary parenchymal ground-glass opacity along with pulmonary consolidation, and the presence of multiple bilaterally diffuse nodules with peripheral lung distribution $[11,12]$. With the fast spread, increased morbidity, and mortality of the COVID-19, tremendous efforts are being made by multiple pharmaceutical giants to discover the drugs, vaccines, or other interventions for prophylaxis or treatment of the disease and to minimize and halt the associated damage it has caused to the entire globe [13]. Currently, there is no definitive treatment available for COVID-19 but on a positive note, recently a few vaccines for COVID19 have been approved in various parts of the world with emergency use authorization based on the limited data available. The entire world is trying out the medicines already in use for other diseases for its treatment but in the rush for treatments, we need to ensure not only the efficacy but also the safety of the drugs under trials. This paper discusses the scenario, impact, and challenges faced by pharmacovigilance monitoring during this pandemic.

\section{The operational structure of pharmacovigilance}

Pharmacovigilance (Pv) is a science of monitoring Adverse Drug Reactions (ADRs). WHO defines it as the "Science and activities relating to the detection, assessment, understanding, and prevention of adverse effects or any other possible drug-related problem" [14]. Pv not only monitors drugs but also the biological products, blood products, herbals, vaccines, medical devices, traditional and complementary medicines in view of identifying new ADRs associated with products and safeguard the patients [15-17]. The process of $\mathrm{Pv}$ includes primarily ADR data collection from the clinics or self-reporting of ADR which is communicated to ADR monitoring centers (AMCs) by filling up the ADR monitoring form/Individual Case Safety Report (ICSR) form which is reviewed, analyzed and causality assessment is done. If found authentic, the ADR is reported to the National Coordination Centre (NCC), Indian Pharmacopoeia Commission (IPC) through an online software called VigiFlow. At NCC, these ICSRs are reviewed to assess the quality of data and if found appropriate, it is forwarded to the "Uppsala Monitoring Centre (UMC), Sweden" which a global ADR monitoring center [16, 18]. UMC analyses the data and adds it up to the global database called "VigiBase", which is maintained by UMC [19]. The NCC also sends these data to the Central Drugs Standard Control Organisation (CDSCO) from time to time or whenever enquired to monitor the safety of various drugs used in India $[20,21]$. The data accumulated and generated from $\mathrm{Pv}$ is basically utilized in various ways like signal generation, post-approval regulation of the drug or vaccine, conducting continued medical education to update the healthcare professionals (HCPs) [18, 20]. WHO Programme for International Drug Monitoring with UMC has set up an online resource database named "VigiLyze" which delivers useful search and analysis functions along with providing a quick and clear overview of global VigiBase data in an instant graphical format [22].

\section{Need of pharmacovigilance in era of Covid-19}

Pharmacovigilance monitoring is a crucial component in monitoring the safety of the therapies being given to COVID-19 patients. Though 
numerous therapies are being used and tested, yet we lack robust data to answers the questions of effectiveness and safety by various drug candidates in view of the rapid drug discovery process at the time of this pandemic. In view of the dire need for an effective drug or vaccine against COVID-19, if we primarily focus the weight on the efficacy of the particular investigational candidate then it would be difficult to ensure the short and long-term safety of these agents. Many of the existing drugs including antimalarials like hydroxychloroquine and chloroquine, antivirals like lopinavir/ritonavir or remdesivir or favipiravir, antiprotozoals like ivermectin, immunomodulators like corticosteroids, and monoclonal antibodies like tocilizumab or sarilumab are being repurposed for the treatment of COVID-19 [13]. For gathering and pooling sufficient information regarding efficacy and ADRs of therapies used against COVID-19, it is essential to record and report all adverse events swiftly and correctly to the pharmacovigilance database which will initiate a timely review of reported data and signal generation or crucial safety data which the HCPs and prescribers are in urgent need of [19]. Currently, the reports of various suspected ADRs for these tried therapies that have reached VigiBase, have been published as a "Report from the WHO Collaborating Centre for International Drug Monitoring, Uppsala Monitoring Centre" which can help HCPs to be cautious and use these therapies rationally [23]. Presently, VigiLyze is also being used to visualize and analyze the safety data swiftly for drugs used in COVID19 [24]. Therefore, ensuring and supporting the collection of highquality data from adverse event reports is crucial for the safe use of pharmacotherapy in these patients.

\section{Reporting of adrs to NCC-IPC}

In India, the ADR can be reported by both HCPs and patients by any of the following means [25]:

1) By filling up the Suspected ADR reporting form available at the PvPI, NCC(IPC) website which is available in English, Hindi, and other Vernacular Languages.

2) Mobile application from Google play store named "ADRPvPI"

3) Helpline Number Managed by NCC PvPI for ADR reporting for the HCPs and general public: 18001803024.

NCC-IPC has formulated a new "suspected ADR reporting form (for drugs used in prophylaxis/treatment of COVID-19) for voluntary reporting by HCPs". Apart from the usual information to be shared in the ADR form this new version has few newly added features to be reported like status on pregnancy, lactation, relevant tests/laboratory data with dates like chest X-Ray, ECG, biochemical examination, ophthalmological examination, test for COVID-19 (RT-PCR test or rapid antibody test), recent travel information, relevant medical/medication history, drug interaction, concomitant medication including a drug used for co-morbidities, and complementary medicines with therapy dates [26]. This additional information and knowledge regarding COVID-19 patients can help assist in the causality assessment in a better way. The above suspected ADR form for drugs used in COVID-19 can be downloaded from the URL: https://www.ipc.gov.in/images/Suspected_ADR_Reporting_Formconverted_2020.pdf

\section{Importance of pharmacovigilance: a learning from hydroxyl- chloroquine episode}

There was an increased demand for hydroxychloroquine (HCQ) and chloroquine (CQ) after the news of it being a magical drug [27]. In the initial in vitro studies, HCQ was found to be effective in the treatment of severe acute respiratory syndrome Coronavirus 2 (SARS-CoV-2) [28, 29]. Even the initial studies have shown a benefit with HCQ and CQ in patients with SARS-CoV-2 [30, 31]. Few studies have shown that HCQ when given with azithromycin led to a reduction of the viral load in COVID-19 patients [32, 33]. Followed by various positive results, the Ministry of Health and Family Welfare, Government of India (GoI) with The Indian Council of Medical Research (ICMR) formulated guidelines dated 23 ${ }^{\text {rd }}$ Mar 2020 to use HCQ in the following people [34]:

1. All asymptomatic healthcare workers working towards containment and treatment of COVID-19 and working in non-COVID hospitals/non-COVID areas of COVID hospitals/blocks.
2. Asymptomatic frontline workers, like surveillance workers posted in containment zones and paramilitary/police personnel involved in COVID-19 related activities.

\section{Asymptomatic household contacts of laboratory-confirmed cases.}

The recommendation also says that it should not be administered in known cases of retinopathy, hypersensitivity to HCQ or 4aminoquinoline compounds, G6PD deficiency, pre-existing cardiomyopathy, and cardiac rhythm disorders, and prophylaxis in children under $15 \mathrm{y}$ of age and pregnancy and lactation [34].

Later on, the COVID-19 Treatment Guidelines Panel, National Institute of Health $(\mathrm{NIH})$ recommended against the use of CQ or HCQ for the treatment of COVID-19, except as a 'trial drug' in clinical trials [35]. A retrospective study in the USA did not identify any significant reduction in mortality or the need for mechanical ventilation with HCQ treatment with or without azithromycin [36]. Similar results were reported by WHO where it stopped the use of HCQ in SOLIDARITY trial concluding that HCQ did not reduce the mortality of hospitalized COVID-19 patients when compared with standard of care [37]. It was found that in patients with COVID-19, a combination of HCQ and azithromycin was associated with QTc prolongation are associated with cardiotoxicity (prolonged QT syndrome) with prolonged use particularly in patients with hepatic and renal dysfunction [38, 39]. Both the drugs have long half-lives hence even sequential use of them should be cautiously done [35]. At the time when all the evidence was against the use of HCQ, an observational study in India gave a ray of hope showing benefit with HCQ prophylaxis among HCPs [40]. Following this, ICMR constituted the National Task Force for COVID-19 which revised the guideline for HCQ use and recommended to be used only in the high-risk cases like [41]:

1. Asymptomatic healthcare workers involved in the care of suspected or confirmed cases of COVID-19.

\section{Asymptomatic household contact of laboratory-confirmed cases.}

The guideline also mentions that the use of HCQ should only be done under the prescription of a registered medical practitioner and the patients are advised to contact the HCP in case of any adverse events. Along with chemoprophylaxis with HCQ, people should follow the recommendations to prevent the spread and worsening of the condition of the patients with COVID-19 [41]. Along with the prophylactic administration of HCQ, the self-reporting of ADRs to the pharmacovigilance centers or Pharmacovigilance Programme of India (PvPI) helpline/Application should be done [42].

The above scenario of HCQ proves the importance of pharmacovigilance in any drug therapy or drug discovery. In the trials, HCQ had mixed results or even showed no benefits however it posed an enhanced possible risk increase in the number of ADRs or drug interactions which could worsen the condition of the patients. ICMR's recommendation to report all the ADRs is a crucial step as this will aid the policymakers to come down to a decision regarding a particular drug candidate whether new or old, to continue or discontinue the use of the particular drug or vaccine candidate in clinical care and research [23].

\section{Covid and pharmacovigilance: challenges}

In current times, pharmacovigilance activities have taken a toll due to the pandemic of COVID-19. Due to the high infectivity of the virus, the usual contact with the patients and the healthcare professionals (HCPs)/residents has diminished to a great extent. The lockdown imposed along with working with a decreased workforce has made it difficult for the AMCs to report the ADRs at the same pace and quantity. Hence, it becomes a collaborative responsibility of the HCPs to come together and ensure proper acquisition and collection of ADRs with timely reporting and causality assessment in the AMCs. Proper reporting and expedited review of ADR reports will help in signal detection and generation of any substantial safety profile of the tried therapies. The causality assessment in COVID-19 patients seems to be a tedious task because of multiple reasons like a large array and variations in clinical signs and symptoms, evolving and newer manifestations, concomitant use of multiple drugs, presence 
of other comorbidities and associated pharmacotherapies, drugdrug and unknown drug-disease interaction in COVID-19 makes it difficult to deal with and may hamper the appropriate causality assessment. The difficulty in causality assessment and ensuring its quality has been an issue as mentioned in the "Report from the WHO Collaborating Centre for International Drug Monitoring, Uppsala Monitoring Centre" [23]. The above report also mentions the issue with restricted data available at present regarding this pandemic and the inconstancy or lack of certainty over other confounders (like the underlying disease). Confounders like extremes of age, pregnancy, and hepato-renal dysfunction can further make the causality assessment onerous. Apart from this, a large number of cases in the hospitals end up in enormous clinical workload which would again lead to a lack of strict ADR monitoring during the pandemic. In the midst of this pandemic, it is not always possible to do all the baseline blood tests before starting any investigational/off-label drug along with following up blood tests to monitor the toxicities which would again make it difficult to review and analyze the ADRs even if they are reported. Ministry of AYUSH under the Ministry of Health and Family Welfare, GoI has recommended self-care guidelines for preventive health measures and boosting immunity which includes various ayurvedic preparations and medicines to be used [43]. However, the guidelines also advise that these ayurvedic preparations do not claim to be a treatment for COVID-19 [43]. In a country like India, many patients do rely on traditional indigenous therapies like Ayurveda, Unani, Siddha, etc and many of these patients do not inform the treating physician about the use of these medicines. Literature also reveals that there is significant use of complementary and alternative therapies in India and patients tend to not inform their treating physician about their alternative medicine use [44, 45]. The use of these alternative medicines might increase the probability of drug interactions and worsen the case scenario. Hence, proper history taking along with appropriate information of all the medications and ADRs is crucial and must be gathered by HCPs for better patient management.

\section{Proposed steps to tackle the issue}

1. Promoting and supporting the AMCs and regional pharmacovigilance centers in the collection of ADRs

2. Strict monitoring of the patients to generate ADR data and to combat under-reporting.

3. Push for electronic or paperless reporting as it is the best possible way at present times.

4. As a large part of the population resides in the rural areas so training and motivating the HCPs and patients in rural health and quarantine centers (for COVID-19) for reporting the ADRs via electronic means would generate a substantial amount of data

5. Conducting webinars for the healthcare professionals to keep them motivated and updated with drug safety and pharmacovigilance.

6. Dedicated pharmacovigilance rapid response team to collect, assess, and report the ADRs.

\section{CONCLUSION}

The current situation of the pandemic has posed challenges for the entire healthcare sector. The pharmacovigilance activities are also hampered. Several old, repurposed drugs and newer drugs are being administered to a large diversity of COVID-19 patients which could lead to numerous ADRs. ADR reporting is a crucial component to ensure the short and long-term safety of the administered therapy in these patients. With the current situation, it is quite difficult to collect and report ADRs caused by medications given to patients with COVID19. Hence it is crucial that HCPs and pharmacovigilance team need to unite to work cohesively and overcome the obstacles in the reporting of ADRs by generation and implementation of new ideas.

\section{FUNDING}

Nil

\section{AUTHORS CONTRIBUTIONS}

All the authors have contributed equally.

\section{CONFLICT OF INTERESTS}

Declared none

\section{REFERENCES}

1. Jin YH, Cai L, Cheng ZS, Cheng H, Deng T, Fan YP, et al. A rapid advice guideline for the diagnosis and treatment of 2019 novel coronavirus (2019-nCoV) infected pneumonia (standard version). Mil Med Res 2020;7:4.

2. World Health Organization (WHO)[internet]. Coronavirus (COVID-19) events as they happen. Available from: https://www.who.int/emergencies/diseases/novel-coronavirus2019/events-as-they-happen. [Last accessed on 16 Jul 2020]

3. Niharika D, Niharika B, Aishwarya T, Nikitha A, Butool R, Ibrahim $\mathrm{M}$, et al. Coronavirus-a virus in learning. Int J Curr Pharm Res 2020;12:7-10.

4. World Health Organization. WHO Coronavirus Disease (COVID19) Dashboard. Available from: https://covid19.who.int/ [Last accessed on 16 Jul 2020]

5. World Health Organization. What are the symptoms of COVID19? Q and A on coronaviruses (COVID-19): WHO TEAM health emergencies preparedness and response. Available from: https://www.who.int/emergencies/diseases/novel-coronavirus2019/question-and-answers-hub/q-a-detail/coronavirus-

disease-covid-19 [Last accessed on 18 Jul 2020]

6. Navdeep K, Simranpreet K, Manjinder K. A review on the fifth pandemic: coronavirus. Asian J Pharm Clin Res 2020;13:25-31.

7. Wang D, Hu B, Hu C, Zhu F, Liu X, Zhang J, et al. Clinical characteristics of 138 hospitalized patients with 2019 novel coronavirus-infected pneumonia in wuhan, China. JAMA 2020;323:1061-9.

8. Kumar T, Dutta S, Sahai R, Khasbage S, Kumar R, Banerjee S. Dermatological manifestations of COVID-19: a review based on existing reports. Int J Curr Res Rev 2020;12:65-8.

9. Zhou P, Yang XL, Wang XG, Hu B, Zhang L, Zhang W, et al. A pneumonia outbreak associated with a new coronavirus of probable bat origin. Nature 2020;579:270-3.

10. Zhou F, Yu T, Du R, Fan G, Liu Y, Liu Z, et al. Clinical course and risk factors for mortality of adult in patients with COVID-19 in Wuhan, China: a retrospective cohort study. Lancet 2020;395:1054-62.

11. Chung M, Bernheim A, Mei X, Zhang N, Huang M, Zeng X, et al. CT imaging features of 2019 novel coronavirus (2019-nCoV). Radiology 2020;295:202-7.

12. Shi H, Han X, Zheng C. Evolution of CT manifestations in a patient recovered from 2019 novel coronavirus (2019-nCoV) pneumonia in Wuhan, China. Radiology 2020;295:20.

13. Clinicaltrialsarena.com. [Homepage in internet]. Coronavirus treatment: Vaccines/drugs in the pipeline for COVID-19. Available https://www.clinicaltrialsarena.com/analysis/coronavirusmers-cov-drugs/ [Last accessed on 20 Jul 2020]

14. World Health Organization [Internet]. Pharmacovigilance; Essential medicines and health products. Available from: https://www.who.int/medicines/areas/quality_safety/safety_ efficacy/pharmvigi/en/ [Last accessed on 20 Jul 2020]

15. WHO pharmacovigilance indicators: a practical manual for the assessment of pharmacovigilance systems. World Health Organization; $2015 . \quad$ Available from: https://www.who.int/medicines/areas/quality_safety/safety_eff icacy/EMP_PV_Indicators_web_ready_v2.pdf [Last accessed on 20 Jul 2020]

16. Kumar L. Pharmacovigilance/Reporting adverse drug reactions: an approach to enhance health surveillance and extending market share by minimizing the chances of drug withdrawals. Int J Pharm Pharm Sci 2015;7:1-7.

17. Dutta S. Pharmacovigilance in India: Evolution and change in scenario in India. Int J Sci Res 2018;7:976-8.

18. Indian Pharmacopoeia Commission. Pharmacovigilance Programme of India; Network: Data Flow. Available from: https://www.ipc.gov.in/PvPI/about.html [Last accessed on 22 Jul 2020]

19. Uppsala Reports. Pharmacovigilance in the age of covid-19; Uppsala Monitoring Centre. Available from: 
https://www.uppsalareports.org/articles/pharmacovigilancein-the-age-of-covid-19/ [Last accessed on 24 Jul 2020]

20. Kalaiselvan V, Thota P, Singh GN. Pharmacovigilance programme of India: recent developments and future perspectives. Indian J Pharmacol 2016;48:624-8.

21. Masurkar P. A need of better pharmacovigilance system in India. Asian J Pharm Clin Res 2017;10:22-4.

22. Uppsala Monitoring Centre. VigiLyze; Get the answers you need. Available from: https://www.whoumc.org/vigibase/vigilyze/ [Last accessed on 25 Jul 2020]

23. Uppsala Monitoring Centre. Descriptive analysis of COVID-19related spontaneous reports from VigiBase: interim results. WHO Collaborating Centre for International Drug Monitoring, dated 22 Jul 2020. Available from: https://www.who.int/ medicines/regulation/medicines-safety/COVID19-PVupdate9.pdf?ua $=1$ [Last accessed on 28 Jul 2020]

24. Uppsala Monitoring Centre. Pharmacovigilance and COVID-19; Medicines safety during COVID-19. Available from: https://www.who-umc.org/global-pharmacovigilance/covid19/ [Last accessed on 29 Jul 2020]

25. Indian Pharmacopoeia Commission. Pharmacovigilance Programme of India; National Coordination Centre, Indian Pharmacopoeia Commission: ADR Reporting Form. Available from: https://www.ipc.gov.in/PvPI/adr.html [Last accessed on 29 Jul 2020].

26. Indian Pharmacopoeia Commission. Pharmacovigilance Programme of India (PvPI) Updates; Suspected ADR Reporting Form for Drugs used in Covid-19. Available from: https://www.ipc.gov.in/images/Suspected_ADR_Reporting_Fo rm-converted_2020.pdf [Last accessed on 30 Jul 2020]

27. Lee J. Market watch. Trump makes the case for chloroquine as a COVID-19 treatment, though it has not been approved by the FDA for this illness 2020 Mar 22. Available from: https://www.marketwatch.com/story/trump-makes-the-casefor-chloroquine-as-a-covid-19-treatment-though-it-has-notbeen-approved-by-the-fda-for-this-illness-2020-03-19 [Last accessed on 01 Aug 2020]

28. Yao X, Ye F, Zhang M, Cui C, Huang B, Niu P, et al. In vitro antiviral activity and projection of optimized dosing design of hydroxychloroquine for the treatment of severe acute respiratory syndrome coronavirus 2 (SARS-CoV-2). Clin Infect Dis 2020;71:732-9.

29. Liu J, Cao R, Xu M, Wang X, Zhang $\mathrm{H}, \mathrm{Hu} H$, et al. Hydroxychloroquine, a less toxic derivative of chloroquine, is effective in inhibiting SARS-CoV-2 infection in vitro. Cell Discovery 2020;6:16.

30. Gao J, Tian Z, Yang X. Breakthrough: chloroquine phosphate has shown apparent efficacy in treatment of COVID-19 associated pneumonia in clinical studies. Biosci Trends 2020;14:72-3.

31. Chen Z, Hu J, Zhang Z, Jiang S, Han S, Yan D, et al. Efficacy of hydroxychloroquine in patients with COVID-19: results of a randomized clinical trial. medRxiv; 2020. https://doi.org/10.1101/2020.03.22.20040758.

32. Gautret P, Lagier JC, Parola P, Hoang VT, Meddeb L, Mailhe M, et al. Hydroxychloroquine and azithromycin as a treatment of COVID-19: Results of an open-label non-randomized clinical trial. Int J Antimicrob Agents 2020;56:105949.

33. Gautret P, Lagier JC, Parola P, Hoang VT, Meddeb L, Sevestre J, et al. Clinical and microbiological effect of a combination of hydroxychloroquine and azithromycin in 80 COVID-19 patients with at least a six-day follow up: a pilot observational study. Travel Med Infect Dis 2020;34:101663.
34. Revised advisory on the use of Hydroxychloroquine (HCQ) as prophylaxis for COVID-19 infection (in supersession of the previous advisory dated 23rd March, 2020). Ministry of Health and Family Welfare, GOI. Available from: https://www.mohfw.gov.in/pdf/Revisedadvisoryontheuseofhy droxychloroquineasprophylaxisforSARSCOVID19infection.pdf [Last accessed on 02 Aug 2020]

35. National Institute of Health. Chloroquine or Hydroxychloroquine. COVID-19 Treatment Guidelines Panel. Available from: https://www.covid19treatmentguidelines.nih.gov/antiviraltherapy/chloroquine-or-hydroxychloroquine-with-or-withoutazithromycin/ [Last accessed on 02 Mar 2021]

36. Magagnoli J, Narendran S, Pereira F, Cummings TH, Hardin JW, Sutton SS, et al. Outcomes of hydroxychloroquine usage in united states veterans hospitalized with COVID-19. Med (N Y). 2020. DOI:10.1016/j.medj.2020.06.001

37. World Health Organization. Q and A: Hydroxychloroquine and COVID-19. Available from: https://www.who.int/news$\mathrm{room} / \mathrm{q}-\mathrm{a}$-detail/q-a-hydroxychloroquine-and-covid-19 [Last accessed on 04 Aug 2020]

38. Institute for Safe Medication Practices. Patient taking hydroxychloroquine right after discontinuing azithromycin develops QTc prolongation and cardiac arrest. ISMP Medication Safety Alert! Acute Care. Available from: https://ismp.org/acute-care/special-edition-medicationsafety-alert-april-9-2020/covid-19\#paragraph-1478. [Last accessed on 05 Aug 2020]

39. American College of Cardiology: Ventricular Arrhythmia Risk Due to Hydroxychloroquine-Azithromycin Treatment For COVID-19. Available from: https://www.acc.org/latest-incardiology/articles/2020/03/27/14/00/ventriculararrhythmia-risk-due-to-hydroxychloroquine-azithromycintreatment-for-covid-19 [Last accessed on 06 Aug 2020]

40. Chatterjee P, Anand T, Singh KJ, Rasaily R, Singh R, Das S, et al. Healthcare workers and SARS-CoV-2 infection in India: a casecontrol investigation in the time of COVID-19. Indian J Med Res 2020;151:459-67.

41. Indian Council of Medical Research. Advisory on the use of Hydroxychloroquine as prophylaxis for SARSCoV2 infection. The national task force for COVID-19; Ministry of Health and Family Welfare, GOI. Available from: https://www.mohfw.gov.in/pdf/AdvisoryontheuseofHydroxyc hloroquinasprophylaxisforSARSCoV2infection.pdf [Last accessed on 06 Aug 2020]

42. Desai MK. Pharmacovigilance and assessment of drug safety reports during COVID 19. Perspect Clin Res 2020;11:128-31.

43. Ayurveda's immunity boosting measures for self-care during COVID 19 crisis. Ministry of AYUSH; Ministry of Health and Family Welfare, GOI. Available from: https://www.mohfw.gov.in/pdf/ImmunityBoostingAYUSHAdv isory.pdf [Last accessed on 06 Aug 2020]

44. Roy V, Gupta M, Ghosh RK. Perception, attitude and usage of complementary and alternative medicine among doctors and patients in a tertiary care hospital in India. Indian J Pharmacol 2015;47:137-42.

45. Sharma A, Agrawal A. Complementary and alternative medicine (CAM) use among patients presenting in outpatient department at tertiary care teaching hospital in Southern Rajasthan, India-a questionnaire based study. Altern Integ Med 2015;4. DOI:10.4172/23275162.1000187. 